Giraldo. V., Matos. D. \& Quintero. W, P. (2020). Entre epistemologias hegemônicas e sabedorias outras: a matemática na encruzilhada. Revista Latinoamericana de Etnomatemática, 13(1), 49-66. DOI: $10.22267 /$ relatem.20131.40

Artículo recibido el 13 de julio de 2020; Aceptado para publicación el 24 de julio de 2020

\title{
Entre epistemologias hegemônicas e sabedorias outras: a matemática na encruzilhada ${ }^{1}$
}

\section{Between hegemonic epistemologies and other knowledge: mathematics at the crossroads}

\author{
Victor Giraldo ${ }^{2}$ \\ Diego Matos $^{3}$ \\ Wellerson Quintaneiro 4
}

No presente cenário político e social global, por um lado, especialmente no Brasil, o negacionismo científico tem contribuído para sustentar necropolíticas; e, por outro lado, formas de estar no mundo associadas a uma noção hegemônica de progresso têm sido associadas à pandemia de covid-19, bem como a outras crises ambientais e sociais iminentes. Nesse sentido, sabedorias outras, especialmente de povos e culturas historicamente invisibilizados, podem inspirar caminhos mais sustentáveis que aqueles associados a epistemologias hegemônicas. Neste texto, propomos algumas reflexões acerca dessas duas facetas de uma perspectiva da modernidade/colonialidade (e.g. Quijano, 2000). Provocados por essas reflexões, e retomando trabalhos anteriores (Giraldo 2018, 2019), discutimos o papel da matemática como disciplina escolar na produção de visões sobre as ciências ditas "exatas" e sobre seu papel nas sociedades contemporâneas. Inspirados na Pedagogia das Encruzilhadas e, mais especificamente, em seus conceitos de rolê epistemológico e de cruzo (Rufino, 2018, 2019), nos desafiamos a reivindicar uma educação matemática em que epistemologias hegemônicas e sabedorias outras não sejam postas em confronto, mas sim chamadas para o jogo.

Palavras-chave: Decolonialidade; Matemática Problematizada; Pedagogia da Encruzilhada

\begin{abstract}
In the current global political and social scenario, on the one hand, especially in Brazil, scientific negationism has contributed to sustain necropolitics; and, on the other hand, ways of being in the world associated with a hegemonic notion of progress have been associated with the covid-19 pandemic, as well as with other imminent environmental and social crises. In this sense, other forms of knowledge, especially the ones from historically invisible peoples and cultures, can inspire paths that are more sustainable than the ones associated with hegemonic epistemologies. In this paper, we propose some reflections upon these two facets from a perspective of modernity/coloniality (e.g. Quijano, 2000). Provoked by these reflections, and resuming previous works (Giraldo 2018, 2019), we discuss the role of mathematics as a school discipline in the production of views on the so-called "exact" sciences and on their role in contemporary societies. Inspired by the Pedagogy of Crossroads and, more specifically, by its concepts of epistemological rolê and cruzo (Rufino, 2018, 2019), we challenge ourselves to claim a mathematical education in which hegemonic epistemologies and other knowledge are not put in confrontation, but are invited to the game.
\end{abstract}

\footnotetext{
${ }^{1}$ As reflexões comunicadas neste texto foram produzidas no Laboratório de Práticas Matemáticas no Ensino (LaPraME), da Universidade Federal do Rio de Janeiro, com a contribuição de todxs xs seus participantes.

${ }^{2}$ Doutor, Universidade Federal do Rio de Janeiro (UFRJ), Rio de Janeiro, Brasil, victor.giraldo@ufrj.br.

3 Doutor, Universidade Federal do Estado do Rio de Janeiro (UNIRIO), Rio de Janeiro, Brasil, diego.matos@uniriotec.br.

${ }^{4}$ Doutor, Centro Federal de Educação Tecnológica Celso Suckow da Fonseca (CEFET/RJ), Rio de Janeiro, Brasil, profmatwellerson@gmail.com.
} 
Keywords: Decoloniality; Problematic Mathematics; Pedagogy of the Crossroads.

\title{
1. CRUZANDO CAMINHOS E HISTÓRIAS
}

\author{
Cadê o cantar dos passarinhos? \\ Ar puro não encontro mais não. \\ É o preço do progresso, pago com a poluição. \\ O homem é civilizado, a sociedade é que faz sua imagem. \\ Mas tem muito diplomado, que é pior do que selvagem. \\ (Candeia, Partido Clementina de Jesus, 1977)
}

A crise provocada pela pandemia de covid-19 se constitui não apenas pelos desafios, sem precedentes recentes, impostos à saúde pública e à ciência em âmbito global, como também por colocar em xeque nossas próprias formas de estar no mundo e de nos relacionarmos em sociedade. Em particular, o Brasil, atualmente entre os países com maiores números de vítimas fatais da pandemia no mundo, vem atravessando esses tempos tendo o negacionismo científico como política de governo (e.g. Roque, 2020); o que tem sustentado a institucionalização de um poder que dita quem pode viver e quem deve morrer - uma necropolítica (Mbembe, 2018). Nesse viés, tem-se defendido amplamente a urgência de se "retornar ao normal" (referindo-se ao reestabelecimento de certas rotinas comerciais) para "salvar a economia". Entendemos que se oculta, na lógica dessa argumentação, uma intencionalidade de naturalizar essa concepção de "economia" como única opção possível. Isto é, esgueira-se aí uma estratégia de ofuscar eventuais possibilidades de inversão dessa lógica: é o regime econômico que precisa ser problematizado, pois se sustenta na submissão da vida ao poder da morte - à qual certos grupos sociais estão mais vulneráveis do que outros. Nesse cenário, por um lado, o negacionismo científico tem contribuído para sustentar uma necropolítica. Por outro lado, formas de se relacionar com o mundo produzidas por uma noção hegemônica de progresso predatório também têm sido associadas à própria disseminação da pandemia de covid-19, bem com a outras crises ambientais e sociais iminentes. Nesse sentido, sabedorias outras, especialmente de povos historicamente invisibilizados, podem inspirar caminhos mais sustentáveis, interpelando lacunas que epistemologias hegemônicas têm deixado em aberto. Com essas reflexões, reverberamos as palavras do mestre Candeia no samba dedicado a Clementina de Jesus - "É o preço do progresso, pago com a poluição. O homem é civilizado, a sociedade é que faz sua imagem." 
Giraldo. V., Matos. D. \& Quintero. W, P. (2020). Entre epistemologias hegemônicas e sabedorias outras: a matemática na encruzilhada. Revista Latinoamericana de Etnomatemática, 13(1), 49-66. DOI: 10.22267/relatem.20131.40

- para questionar que sentidos de "civilização" e de "progresso" têm operado nas sociedades contemporâneas: Nossa civilização progride, mas em direção a que lugar? Que corpos e saberes estão excluídos desse lugar?

Então, qual é o lugar da ciência (dita hegemônica) nesse contexto? Neste texto, não buscamos responder a tal questão, mas propomos algumas reflexões acerca dessas duas facetas, a partir de uma opção pela perspectiva da modernidade/colonialidade (e.g. Quijano, 2000). Essa perspectiva emerge no campo das ciências sociais e humanas, como uma posição política e epistêmica articulada com lutas e movimentos sociais, especialmente a partir do início da década de 1990, em diversos países da América Latina. Posteriormente, o debate decolonial entra no campo educacional, se expressando nas chamadas pedagogias decoloniais (e.g. Walsh, 2013).

A incorporação do debate decolonial no campo da Educação Matemática no Brasil pode produzir entrelaçamentos potentes com outras perspectivas político-epistêmicas, em particular, com as ideias precursoras de Ubiratan D’Ambrósio ao conceber o Programa Etnomatemática. Nas palavras do autor, "o grande motivador do programa de pesquisa [...] é procurar entender o saber/fazer matemático ao longo da história da humanidade, contextualizado em diferentes grupos de interesse, comunidades, povos e nações" (D’Ambrosio, 2001, p. 17-18). A opção por seguir outros caminhos neste trabalho demarca que não objetivamos considerar tais grupos como contextos de investigação, em que se manifestam a singularidade do "saber/fazer matemático" e a universalidade da "história da humanidade". As discussões iniciadas neste texto pretendem tensionar e alargar a delimitação epistemológica da matemática como campo de conhecimento, bem como as formas por meio das quais essa delimitação pode conformar práticas educacionais e formativas na escola e na universidade referenciadas em culturas hegemônicas. Pretendemos tensionar, ainda, as próprias noções de "história" e de "humanidade", frequentemente apresentadas como perspectivas únicas para explicar o mundo e pensar a vida, mesmo quando intencionam legitimar saberes e práticas de grupos subalternizados.

Provocados por essas reflexões e retomando trabalhos anteriores (Giraldo 2018, 2019), discutimos o papel da matemática como disciplina escolar na produção de visões sobre as ciências ditas "exatas" e sobre seu papel nas sociedades contemporâneas. Inspirados na 
Pedagogia das Encruzilhadas proposta por Rufino $(2018,2019)$ e, mais especificamente, em seus conceitos de rolê epistemológico e de cruzo, nos desafiamos a reivindicar uma educação matemática em que epistemologias hegemônicas e sabedorias outras não sejam postas em confronto, mas sim chamadas para o jogo - isto é, no sentido defendido pelo autor, referenciado nas sabedorias da capoeira, são entrelaçadas em ações de desvio mas também de avanço, de esquiva mas também de contragolpe lançado nos vazios deixados, caracterizando uma dinâmica que é ambivalente e que não visa à destruição do outro.

\section{COLONIALIDADE DO PODER E NEGACIONISMO COMO POLÍTICA}

Quijano (2000) caracteriza a colonialidade do poder como a invenção de um sistema de hierarquização social de seres, saberes e visões de mundo, baseado sobretudo em categorias de "raça", como parte de um projeto de dominação e exploração centrado no capital. Os autores vinculados à chamada Rede Modernidade/Colonialidade referem-se à colonialidade como um padrão de poder que emergiu do colonialismo territorial e administrativo do continente americano, mas sobrevive a este, operando nas formas como o trabalho, o conhecimento, a autoridade e as relações intersubjetivas se engendram e se articulam entre si (e.g. Lander, 2001).

Para esses autores, a colonialidade se sustenta no mito da modernidade eurocêntrica que, como aponta Dussel (1992), se constitui a partir do auto entendimento de superioridade da civilização moderna, com base em uma narrativa histórica segundo a qual a humanidade evolui, linear e universalmente, em direção ao progresso, representado por uma idealização da sociedade europeia - invisibilizando todas as outras histórias que coexistiam antes da colonização do continente americano. Tudo que se alinha a esse caminho linear e universal para o progresso é então alçado a um patamar de avanço e desenvolvimento, enquanto corpos, sabedorias e visões de mundo outras são relegadas a um lugar de primitivismo e atraso. Além disso, os próprios sujeitos são culpabilizados por suas supostas condições de atraso, que são atribuídas a certas deficiências ou incapacidades inerentes. Desta forma, a modernidade é entendida como uma invenção da colonialidade, que tem servido, nos últimos séculos, para justificar a imposição de processos civilizatórios aos povos classificados como "primitivos" e "bárbaros”. Nesses processos, todas as violências são necessárias e moralmente justificadas 
Giraldo. V., Matos. D. \& Quintero. W, P. (2020). Entre epistemologias hegemônicas e sabedorias outras: a matemática na encruzilhada. Revista Latinoamericana de Etnomatemática, 13(1), 49-66. DOI: 10.22267/relatem.20131.40

para tirar esses povos do atraso, sob o pretexto de levá-los na direção única do progresso. Assim, o mito da modernidade eurocêntrica se caracteriza pela naturalização das epistemologias e racionalidades hegemônicas, que são impostas como opções únicas.

A perspectiva da modernidade/colonialidade nos ajuda a refletir sobre como, no Brasil de hoje, a alegada necessidade de "proteger a economia" tem sido persistentemente usada para justificar o sacrifício de um grande número de vidas. A lógica do capitalismo é naturalizada como única opção de "caminho para o progresso"; e as vidas sacrificadas são, em maioria, de grupos sociais subalternizados nas hierarquias sociais produzidas por processos de colonialidade do poder. Em prol desse "único caminho possível para o progresso”, assim como se justificaram as invasões dos continentes africano e americano para "tirar seus povos do atraso", justificam-se, por exemplo, a destruição de biomas nativos e o genocídio de povos autóctones cujos modos de vida se entrelaçam, indissociavelmente, com esses ambientes; assim como o sacrifício de trabalhadoras e trabalhadores compelidos a exercer atividades que constituem riscos iminente para suas vidas.

Para sustentar essas investidas, tem-se adotado no Brasil o negacionismo científico como política de governo (Roque, 2020). Tal política inclui, como estratégias, não apenas negar resultados de pesquisas científicas que possam ser inconvenientes para seus propósitos, como, sobretudo, empreender uma campanha de desqualificação da própria ciência como geradora de verdades e produtora de soluções para demandas e inquietações da sociedade.

$\mathrm{Na}$ continuidade deste texto, esboçaremos algumas reflexões com respeito a formas como a matemática pode reforçar políticas de colonialidade do poder na escola e na ciência - bem como, sobretudo, a possíveis posicionamentos e posturas que abram caminhos para mobilizarmos outra matemática e outra educação que problematizem tais políticas.

\section{COLONIALIDADE DA NATUREZA E DA VIDA}

O mito da modernidade eurocêntrica (Dussel, 1992) implica em uma concepção de que tudo que se não alinha a um caminho linear e universal em direção ao progresso é relegado a um lugar de primitivismo e atraso. A partir daí, se justificam quaisquer violências, genocídios, epistemicídios e devastações ambientais entendidos como necessários para atingir o progresso. A noção de colonialidade da natureza e da vida (Walsh, 2008) possibilita 
expressar um entendimento de que as formas de estar no mundo referenciadas nas culturas contemporâneas hegemônicas se sustentam em dicotomizações entre "humanidade" e "natureza", entre "razão" e "corpo", entre "civilização" e "barbárie”. Essas concepções colocam a "natureza" como algo de que a "humanidade" não faz parte e, mais do que isso, algo que precisa ser controlado ou subjugado pela "humanidade". Tal subjugação seria, então, uma maneira de naturalizar o direito ao uso e à exploração da natureza em favor do "progresso". Nesse sentido, afirma Ailton Krenak:

E nós criamos essa abstração de unidade, o homem como medida das coisas, e saímos por aí atropelando tudo, num convencimento geral até que todos aceitem que existe uma humanidade com a qual se identificam, agindo no mundo à nossa disposição, pegando o que a gente quiser. Esse contato com outra possibilidade implica escutar, sentir, cheirar, inspirar, expirar aquelas camadas do que ficou fora da gente como "natureza", mas que por alguma razão ainda se confunde com ela. (Krenak, 2019, p. 33)

Paradoxalmente, a mesma dicotomia que separa a "humanidade" da "natureza" torna o projeto colonial ainda mais refém dela, pois acentua sua dependência ao compreender a natureza como fonte de exploração. Nesse sentido, não há como discutir a problemática da natureza sem implicá-la à vida. Destacando a dimensão cosmológica da colonialidade, Walsh (2008) afirma que, ao desconsiderar a relação milenar entre mundos biofísicos, humanos e espirituais, negando a relação ancestral que situa o homem como parte da natureza e que dá sentido ao universo e a seu próprio viver, a colonialidade da natureza se manifesta como a colonialidade da própria vida em si. Nesse ataque à vida, formas de existência classificadas como "selvagens", "bárbaras" ou "não civilizadas" demarcam a resistência ancestral de povos que compreenderam a natureza como filosofia de vida em sua integralidade, não como "meio ambiente" ou como "recurso".

Como ameaça que concebe a vida de forma despedaçada, o projeto colonial da modernidade, para hierarquizar saberes e corpos, apropriou-se também do tempo, cindindo a vida presente como simples passagem entre um passado sepultado como "atraso" e um futuro perspectivado como "progresso". As sabedorias de povos ancestrais, por outro lado, nos sugerem "pensar o presente de forma alargada, que nos permite também transgredir com a linearidade histórica que achata o presente (potência do ser e suas invenções em interação com o espírito do tempo) entre passado e futuro" (Rufino, 2019, p. 25). Como instituições 
Giraldo. V., Matos. D. \& Quintero. W, P. (2020). Entre epistemologias hegemônicas e sabedorias outras: a matemática na encruzilhada. Revista Latinoamericana de Etnomatemática, 13(1), 49-66. DOI: 10.22267/relatem.20131.40

que escrevem a história do vivido em sociedade, acreditamos que a ciência e a escola podem construir outras relações com o tempo, inspiradas em sabedorias nas quais a ancestralidade é remetida como memória coletiva que (re)pensa a (re)existência - em todas as formas como isso pode ser lido -, de maneira que a delimitação linear entre passado, presente e futuro, talvez, nem faça mais sentido. Nessa direção, afirma Mateus Aleluia:

Nós somos os ancestrais e nós somos os futuristas. É a verdadeira volta. É como se fosse a cobra picando a própria cauda. A gente quando fala no ancestral, a gente fala também naquele que há de vir. Uma coisa está totalmente ligada à outra. Aquilo que é aquilo que já foi. Aquilo que vai ser é o que está sendo e o que já foi também. A ancestralidade é realmente a nossa forma de estar na vida, tanto com a representação às vezes como se fôssemos passado, às vezes como se estivéssemos no presente, e às vezes a gente faz uma projeção para o futuro. Essa é a nossa forma ancestral de existir. (Aleluia, 2013)

\section{MATEMÁTICA PROBLEMATIZADA COMO AÇÃO DECOLONIAL}

Os autores vinculados à chamada Rede Modernidade/Colonialidade destacam, ainda, que com a colonialidade emerge também a decolonialidade, como uma forma de resistir, de sustentar e (re)construir caminhos de luta contínuos para tirar da invisibilidade epistemologias outras e atuar a partir dessa visibilização. Como propõe Walsh (2013), o uso do termo decolonialidade (em lugar de descolonialidade) visa a evidenciar uma opção epistemológica e política que se opõe a expectativa de estado nulo de colonialidade - como se fosse possível passar de um momento colonial a outro não colonial, livre de seus traços e efeitos. A decolonialidade se refere, portanto, a posicionamentos, posturas, horizontes e projetos de resistência, transgressão, intervenção e insurgência, em que nos desafiamos a desaprender a pensar a partir das referências das epistemologias hegemônicas como opções únicas e a aprender a atuar em seus arredores, em suas fissuras, em suas rachaduras. Assim, a decolonialidade não é entendida como um substantivo fixo, mas como verbalidades em que se movimentam essas ações.

Em trabalhos anteriores (Giraldo, 2018, 2019), buscando tensionar discursos convencionais sobre formação de professores de matemática, pautados pelo estabelecimento de dicotomias como conteúdo versus pedagogia, universidade versus escola, teoria versus prática, propomos uma noção de matemática problematizada:

Pelo termo matemática não problematizada, referimo-nos a uma concepção da matemática estabelecida, como um corpo de conhecimentos que sempre foi e sempre 
será da forma que é hoje, ou que evolui linearmente de um estado "mais atrasado" para um estado "mais avançado", por meio da inspiração isolada de "gênios com talento inato". Por matemática problematizada, em contrapartida, entendemos uma concepção de possibilidades matemáticas, situadas em diversos contextos e práticas históricos e sociais de produção e de mobilização de saberes e de formas de estar no mundo. (Giraldo, 2019, p. 8, grifos no original)

De uma perspectiva decolonial, entendemos a noção de matemática problematizada como uma forma de refletir sobre conhecimentos matemáticos a partir de seus processos plurais de produção, de questionar a matemática acadêmica, de referência eurocêntrica, como ótica dominante para descrever o mundo. Compreendendo que "a validação de critérios de conhecimento não é exterior aos conhecimentos que a validam” (Santos, 2019, p. 65), reconhecemos que a própria noção do que é matemática provém de referência eurocêntrica. Entretanto, tal forma de conhecimento não pode invisibilizar outras sabedorias e, sobretudo, sujeitos e lugares de produção - incluindo uma matemática que é mobilizada e produzida em espaços e tempos escolares.

Nesse sentido, questionamos tanto a própria epistemologia eurocêntrica do conhecimento matemático como opção única quanto a ontologia dos saberes, quando destacamos que todos os sujeitos em suas vidas, nos lugares de alunos ou de professores em espaços educacionais formais, também são produtores de sentidos e de saberes, que atravessam e são atravessados por uma matemática de referência hegemônica. Então, não se trata de negar a matemática de referência epistemológica hegemônica, mas sim de enxergar que há sabedorias outras no jogo e, portanto, de questionar essas epistemologias hegemônicas como formas exclusivas de produção de saberes, assim como de reconhecer que há diferentes atores em um processo dinâmico de produção e ressignificação de ideias matemáticas. Assim, não se trata de defender a substituição da matemática como disciplina escolar ou como ciência, mas de evidenciar, legitimar e provocar tensionamentos nessa matemática a partir dos caminhos possibilitados por sabedorias outras.

Esse posicionamento decolonial nos parece importante como instrumento para pensar como pode ser a natureza de nossas lutas, enquanto professores dessa matemática hegemônica. Nem sempre a melhor estratégia de luta é o confronto direto - que, neste caso, poderia ser interpretado como um rompimento radical com uma matemática hegemônica e sua 
Giraldo. V., Matos. D. \& Quintero. W, P. (2020). Entre epistemologias hegemônicas e sabedorias outras: a matemática na encruzilhada. Revista Latinoamericana de Etnomatemática, 13(1), 49-66. DOI: 10.22267/relatem.20131.40

substituição por sabedorias outras, ou com deixar de ser professor dessa matemática, por vezes, opressora.

\title{
5. A MATEMÁTICA NA ENCRUZILHADA
}

\author{
Bifurcação, entroncamento, contramão \\ São ruas sem fim \\ Vias de fato aos pés de quem \\ Desrespeitou sinais e atravessou ileso \\ (Metá Metá, Vias de Fato, 2011)
}

As reflexões sobre matemática problematizada, discutidas na seção anterior, não propõem a negação do que hoje é delimitado epistemologicamente como matemática, mas expõe uma problemática que remete a outras pedagogias, implicadas no compromisso com formas de vida subalternizadas pelo projeto colonial. Conforme a pedagogia decolonial proposta por Walsh (2013), entrelaçar o pedagógico e o decolonial requer uma prática de desaprender o que foi imposto pela colonialidade e reaprender para reconstruir o ser. Entendemos que, em seu sentido original, a autora pretende marcar que esse exercício de desaprender a pensar a partir de uma perspectiva universal e normativa não significa esquecer o que foi aprendido, mas tensionar essa aprendizagem de modo a produzir outras formas de (re)existência. Nessa perspectiva, a dimensão decolonial da matemática problematizada não nega a legitimidade epistemológica da ciência, entretanto, não abre mão de tensionar seu caráter eurocentrado como possibilidade de problematizar o lugar hegemônico que ocupa, em diálogo com sabedorias e existências outras que produzam novas formas de vida.

Ao problematizar a matemática (como disciplina escolar e como campo de conhecimento) a partir dessa perspectiva, pretendemos encarnar uma dimensão ambivalente que não nega nenhum caminho como possibilidade - o que está no cerne da Pedagogia das Encruzilhadas de Rufino (2019), que discute questões do racismo, do colonialismo e da educação tendo o orixá Exu como referência teórica e metodológica. No projeto proposto pelo autor, o conceito de cruzo é apresentado como possibilidade de transgressão de sentidos normativos, a partir de relações pluriversais que os atravessam com perspectivas historicamente subalternizadas, provocando deslocamentos que reinventam a vida respondendo eticamente àqueles que foram subalternizados pelo projeto colonial e arrebatando aqueles que enxergam o mundo 
por lentes hegemônicas e universais. A encruzilhada, portanto, reinscreve como invenção o que foi projetado como impossibilidade.

A matemática problematizada, pensada na perspectiva do cruzo, não opera propondo substituir a matemática eurocêntrica por outros referenciais não hegemônicos, nem sugerindo o negacionismo científico ou o descrédito de resultados que estejam referenciados em epistemologias dominantes. Tampouco, pensar a matemática nesta encruzilhada não implica em uma tentativa de tirar sabedorias e práticas invisibilizadas de um suposto lugar de “atraso", por meio de sua observação a partir de lentes acadêmicas e hegemônicas que visem a legitimá-las com o rótulo de "matemática(s)" - que, muitas vezes, nem é reivindicado pelas próprias culturas originárias. O caminho de encontro que propomos problematiza a matemática que está estabelecida, atualmente, em espaços normativos como a ciência, a escola ou a universidade, ocupando os vazios por ela deixados mediante o cruzo com outras perspectivas de conhecimento e de existência, desestabilizando seu lugar de hegemonia e reivindicando o alargamento de possibilidades para pensar uma matemática de forma implicada à vida.

Compreendendo que a decolonialidade - ao invés de "descolonialidade" - demarca uma opção política segundo a qual não há um estado nulo de colonialidade (Walsh, 2013), a dimensão decolonial da matemática problematizada recorre a ações táticas que colocam a pretensa universalidade da matemática hegemônica diante da pluriversalidade de princípios explicativos de mundo, que desmontam sua suposta linearidade com a ambivalência do cruzo. Rufino (2018) destaca que saberes pensados em encruzilhadas são sabedorias de frestas que compreendem tanto a esquiva quanto o golpe como ações que só são possíveis a partir da ginga e da dinâmica do jogo, apresentando a noção de rolê epistemológico para descrever movimentos que se lançam nos vazios deixados como estratégias de não apreensão de um modo de saber por outro reivindicado como único.

A noção de rolê epistemológico inspira-se nas sabedorias da capoeira para propor ações de desvio e avanço. Imprime, nesse sentido, a lógica do jogo. Os rolês caçam tempos/espaços para a prática das virações, esquiva-se, rola-se de um lado para o outro, finge que vai, mas não vai e aí se dá o bote, certeiro, eis que o cruzo então acontece. O rolê é ao mesmo tempo o movimento de desvio, de fuga, de ganho de espaço e de montagem de estratégias para a operação de golpes. A lógica do jogo não presume a aniquilação do outro com que se joga, mas permite a sedução, o destronamento, o drible 
Giraldo. V., Matos. D. \& Quintero. W, P. (2020). Entre epistemologias hegemônicas e sabedorias outras: a matemática na encruzilhada. Revista Latinoamericana de Etnomatemática, 13(1), 49-66. DOI: $10.22267 /$ relatem.20131.40

e o golpe. Se tentar me prender, eu giro; pronto escapuli, já estou do outro lado! Assim, o conceito encarna as manhas do jogo de corpo para praticar no campo dos conhecimentos outras virações que potencializem a prática das frestas. (Rufino, 2018, p. 83 , grifos do autor)

A matemática problematizada propõe chamar a matemática para a dinâmica ambivalente do jogo, praticando o rolê epistemológico para esquivar-se de seus sentidos normativos e, em contragolpe, ocupar os vazios por ela deixados com problematizações que a atravessam com outras epistemologias e com outras formas de vida. Com o perdão do pleonasmo, joga-se o jogo com a ciência que, orgulhosamente, se esforça para enxergar "a matemática em tudo", para lembrá-la que qualquer pretensa onipresença, de forma também redundante, habita na pluriversalidade de presenças e não na universalidade de um caminho único. Diante da imobilidade de resultados prontos que a matemática apresenta, descobre-se seu inacabamento - no sentido de tirar debaixo dos panos - em um giro que o reinscreve como movimento que impulsiona novas "descobertas". Para a epistemologia que se apresenta como ciência da certeza, a dúvida é lançada como princípio que constitui seu próprio fazer, contragolpe que tensiona a matemática como produtora de perguntas e não como reprodutora de respostas. A pedagogia apresentada por Rufino (2019) invoca Exu como princípio da dúvida e do inacabamento, aquele que é a resposta enquanto dúvida, instaurada para destronar qualquer forma de obsessão pela certeza; aquele que simboliza o inacabamento da mobilidade contínua de saberes cruzados, abrindo caminhos enquanto possibilidades. Nesse sentido, a matemática problematizada, pensada na perspectiva do cruzo, se coloca como uma problemática epistemológica que reconhece a dúvida e o inacabamento como partes estruturantes de uma ciência que se problematiza, não como elementos transitórios para alcançar o "progresso", mas como dimensões que constituem sua própria epistemologia.

Destacamos que problematizar a matemática nesta encruzilhada sugere rolês epistemológicos e aponta, também, como demanda futura, reflexões sobre ontologias implicadas nesse saber. Ao discutir a legitimidade da filosofia africana, Ramose (2011) observa que a disposição filosófica do ser costuma ser retratada a partir de sua particularidade, como condição ontológica existencial que exclui sua implicação com o outro ou que concebe esse outro como ameaça a especificidade do ser. $\mathrm{O}$ autor alerta que uma perspectiva particularista do ser pode reivindicar o direito de se impor como experiência única, fundamento do conceito de 
universalidade que suprime a pluriversalidade do ser. No cruzo com Ramose (2011), acreditamos que a matemática problematizada pode se configurar, também, como uma problemática ontológica. Nesse jogo, a matemática não escolhe com quem quer jogar, sob o escudo de casos particulares e contraexemplos escolhidos, estrategicamente, para exemplificar ou refutar quem pode participar de sua dinâmica; a particularidade é aqui compreendida como parte da ambivalência do jogo, condição primeira do ser que abre caminhos para a pluriversalidade de possibilidades que problematizam a matemática.

\title{
6. A EDUCAÇÃO MATEMÁTICA NA ENCRUZILHADA
}

\author{
Mesmo pisando firme em chão de giz \\ De dentro pra fora da escola \\ é fácil aderir a uma ética e uma ótica \\ Presa em uma enciclopédia de ilusões bem selecionadas \\ E contadas só por quem vence \\ Pois acredito que até o próprio Cristo \\ era um pouco mais crítico em relação a tudo isso \\ E o que as crianças estão pensando? \\ Quais são os recados que as baleias têm para dar a nós \\ seres humanos, antes que o mar vire uma gosma? \\ Cuide bem do seu Tcheru \\ Na aula de hoje veremos Exu \\ Voando em Tsuru \\ Entre a boca de quem assopra \\ e o nariz de quem recebe o Tsunu \\ (Kiko Dinucci e Edgar, Exu nas Escolas, 2018)
}

O projeto colonial de poder foi erguido com base em uma educação que fecha caminhos, escrevendo, nos livros didáticos, histórias oficiais apresentadas como opções únicas, de maneira que, diante da invisibilidade de outras possibilidades, "De dentro pra fora da escola é fácil aderir a uma ética e uma ótica / Presa em uma enciclopédia de ilusões bem selecionadas / E contadas só por quem vence". Uma educação matemática pensada na encruzilhada demanda outras políticas, éticas e estéticas, perspectivas em que a matemática rompe com a ética escravizada e escravizante do erro ou do acerto, dicotomia que orbita uma moral cindida entre o bem e o mal em defesa da superioridade de uma verdade (Cammarota, Rotondo \& Clareto, 2019). Como no canto de Elza Soares, "Exu nas Escolas" reivindica uma educação transgressora inspirada naquele que tudo come, mastiga e engole para cuspir de 
Giraldo. V., Matos. D. \& Quintero. W, P. (2020). Entre epistemologias hegemônicas e sabedorias outras: a matemática na encruzilhada. Revista Latinoamericana de Etnomatemática, 13(1), 49-66. DOI: 10.22267/relatem.20131.40

forma transformada, dimensão ética descrita por Rufino (2018) como um ato comprometido com uma resposta responsável cedida ao outro que nos interpela.

Em muitos momentos, reféns do pensamento moderno, a escola e a ciência não assumiram o compromisso de abordar a problemática do conhecimento de forma implicada ao outro, reproduzindo discursos enunciados para si, dialogando pouco com a sociedade e não legitimando saberes produzidos fora de seus muros - eximindo-se de jogar o jogo com esses saberes. Conforme destacado por Walsh (2008), a colonialidade do saber se enraizou no sistema educativo, da escola até a universidade, de maneira que o conhecimento europeu foi legitimado como o marco científico-acadêmico-intelectual, consolidando a educação como projeto de poder que normatiza essa concepção de conhecimento e que regula quem está no interior de suas fronteiras. Nesse contexto, a matemática é frequentemente reproduzida de forma não problematizada, recusando-se a entrar no jogo ou, ainda quando participa dele, decidindo quem pode (e quem não pode) jogar, evidenciando o receio de expor os vazios de uma jogadora que, ao se apresentar como uma ciência dura, admite que não tem ginga.

Ao não chamar todos para o jogo, a ciência - e seu desdobramento na escola - determinou as fronteiras do conhecimento de forma tão rígida que se tornou incompreensível para grande parte da sociedade, impondo seu lugar de poder para legitimar epistemologias, sem se preocupar com a compreensão de seus critérios de validade. Nesse cenário, o fortalecimento do negacionismo científico escancara uma arapuca que se volta contra a própria ciência que, igualmente, negou-se a entrar no jogo e excluiu quem dele não podia participar. Ao se referenciar em uma cultura eurocêntrica, proposta como caminho hegemônico e universal, a ciência alimentou dicotomias e, consequentemente, hierarquias - homem versus natureza, razão versus corpo, atraso versus progresso, entre outras - que produziram sentidos para o negacionismo e legitimaram as narrativas de caminho único para o progresso da modernidade.

Ao situar a ciência no centro desse debate, não propomos seu relativismo nem nos alinhamos a correntes anticientíficas; em uma direção oposta, tais reflexões revelam o reconhecimento de sua importância para a sociedade e para a educação. O negacionismo reivindica dogmas admitidos como verdades universais, desqualifica argumentos e, portanto, nega a vida. Entretanto, uma vez que o negacionismo está presente na sociedade, é preciso assumi-lo 
como uma questão a ser enfrentada, também, na escola e nos espaços e tempos de formação, respondendo de forma responsável àqueles que são capturados pelos efeitos da colonialidade e praticando o cruzo como forma de transgressão. Nos atravessamentos promovidos por pedagogias de encruzilhadas, o fetichismo obcecado por verdades é destronado pela dúvida, elemento propulsor de uma dinâmica ambivalente em que "toda ignorância é ignorância de um dado tipo de conhecimento e todo conhecimento consiste em ultrapassar um certo tipo de ignorância” (Santos, 2019, p. 69). Como afirmam Simas \& Rufino (2018), pensar a produção de saberes a partir da prática do cruzo exige apropriar-se da atitude do pesquisador cambono 5 - aqui estendido, também, para a figura do educador -, aquele que se coloca em uma condição de não saber, praticando um saber cismado que se mantém fiel à dúvida e que se abre para o cruzo, em uma atitude de disponibilidade ao outro que compreende a educação como experiência e a experiência como acontecimento.

A educação matemática pensada na encruzilhada reivindica, portanto, a mobilização de outra educação e de outra matemática. Rufino (2018) afirma que, nesse sentido, a educação é concebida como um devir que apresenta caminhos como possibilidades para a reinvenção de seres, comprometida com a justiça cognitiva/social e com a vida em sua diversidade. Na possibilidade que apresentamos, diante da educação matemática problematizada na perspectiva do cruzo, o pesquisador/educador cambono não teme o jogo pois sabe lidar com a ginga, uma vez que reconhece a dúvida como parte integrante das práticas matemáticas que se realizam na escola e na ciência.

\section{POR UMA EDUCAÇÃO MATEMÁTICA DA ENCRUZILHADA}

A posição que assumimos neste texto não é a de confronto com uma ciência e uma matemática hegemônicas, tampouco de alinhamento com relativismos e negacionismos científicos que sustentam projetos de colonialidade do poder e de necropolítica (manifestados, no caso do enfrentamento à pandemia de covid-19 no Brasil, por exemplo,

\footnotetext{
${ }^{5}$ Simas e Rufino (2018) descrevem o cambono como uma espécie de auxiliar de pai de santo e das próprias entidades, que trabalha, nos terreiros de candomblé, na interlocução com todos os saberes/fazeres necessários para a abertura de caminhos. Atuando quase como um "faz tudo", praticando mesmo aquilo que ainda não sabe, o cambono está sempre disponível para atuar em função do outro e ser afetado por ele.
} 
Giraldo. V., Matos. D. \& Quintero. W, P. (2020). Entre epistemologias hegemônicas e sabedorias outras: a matemática na encruzilhada. Revista Latinoamericana de Etnomatemática, 13(1), 49-66. DOI: 10.22267/relatem.20131.40

pela negação de modelos matemáticos, pelo descrédito de medidas de contensão de contágio ou pela imposição de falsas curas).

Propomos, sim, convocar para o jogo essa matemática hegemônica na ciência e na escola; ocupar os vazios deixados em seus movimentos, por meio do cruzo com outras sabedorias e formas de vida; atuar em suas fissuras e brechas, tornando-as lugares de potência e de (re)existência. Propomos, desta forma, desestabilizar pretensas posições de universalidade da matemática - sobretudo, enxergando sabedorias e corpos que são historicamente excluídos desse suposto universo. É entrando no jogo que a ciência hegemônica pode se desnudar publicamente e expor sua capacidade de problematizar continuamente suas próprias verdades, em lugar de se fantasiar como dura e sem ginga. Somente despindo-se dessa fantasia que a ciência pode resistir à submissão a projetos de colonialidade do poder, da natureza e da própria vida; e pode, também, se diferenciar dos negacionismos que se sustentam no culto a dogmas sacralizados que nunca podem ser problematizados. Como já observamos, o que propomos:

não corresponde meramente a outra versão da mesma história, em que os povos colonizados contemplam passivamente a aproximação das caravelas carregando os dispositivos civilizatórios que apagarão suas culturas. A narrativa que propomos é uma subversão da história, na qual, em um movimento decolonial, esses povos tomam consciência da chegada das caravelas, apropriando-se delas, desmontando-as, subvertendo o uso de suas peças e usando-as em caminhos de resistência e de insurgência que produzem possibilidades de fortalecimento de poderes, valorização de saberes, afirmação de seres, de corpos e de formas de viver e de estar no mundo. (Giraldo \& Fernandes, 2019, p. 270, grifos no original)

Assim, reivindicamos outra educação matemática - não uma educação que exponha uma matemática feita de fatos prontos e acabados, mantidos intocáveis em lugares sacralizados; mas sim uma matemática na qual seja possível intervir, se apossar de suas peças e subverter seus usos. Essa não é uma matemática que está "na encruzilhada", no sentido de estar em uma situação de impasse, um estado transitório de deficiência, do qual deve se desvencilhar para obter certezas perenes, que lhe permitam prosseguir em um caminho estável em direção ao progresso.

Ao contrário, o que exortamos é uma matemática da encruzilhada, uma matemática que não somente habita na encruzilhada, mas que faz, sobretudo, dessa habitação um lugar de 
potência. Para a matemática da encruzilhada, o que importa é o problema e a dúvida - e não o entendimento único, a resposta, a certeza -, pois é no problema e na dúvida que está a potência de produzir entendimentos plurais, de mobilizar saberes outros, que são permanentemente convocados para o jogo, entrelaçados em movimentos de desvio e de avanço, de esquiva e de contragolpe. Tendo esses movimentos como sua própria materialidade, a matemática da encruzilhada se constitui na problematização, na ambivalência, na pluriversalidade e no entrelaçamento de caminhos como possibilidades.

Que sejam eternos todas as pessoas, grupos e espaços que lutam e lutaram contra as restrições de liberdade, a opressão, a escravidão, o genocídio. Todas as revoltas, fugas e submissões de resistência. A todas que queimaram engenhos, que se recusaram às missões, que envenenaram e subverteram ordens. A todos que resistiram. (...) Todas as Aldeias, Quilombos, Aimorés, Caciques e Pajés, aos Caboclos, Erês, Pretos Velhos, toda a linha de Umbanda, ao meu pai Oxalá, e todos os Orixás. (...)

Outros tantos, no caminho pelo qual lutamos e acreditamos. A nossos ancestrais! Por nossos ancestrais! Höröyá!

(Höröyá, Abertura Höröyá, 2016)

\section{REFERÊNCIAS}

Aleluia, M. (2013, junho 02). Cinco Sentidos - TVE-Ba [Vídeo]. Recuperado de https://www.youtube.com/watch?v=1_tqq6xcrHk 
Giraldo. V., Matos. D. \& Quintero. W, P. (2020). Entre epistemologias hegemônicas e sabedorias outras: a matemática na encruzilhada. Revista Latinoamericana de Etnomatemática, 13(1), 49-66. DOI: 10.22267/relatem.20131.40

Cammarota, G., Rotondo, M. \& Clareto, S. (2019). Formação docente: exercício ético estético político com matemáticas. Perspectivas da Educação Matemática, 12(30), 679-694.

D’Ambrosio, U. (2001). Etnomatemática: elo entre as tradições e a modernidade. Belo Horizonte, Brasil: Autêntica.

Dussel, E. (1992). 1492: El encubrimiento del otro. Hacia el origen del mito de la modernidad. Madrid, España: Nueva Utopía.

Giraldo, V. \& Fernandes, F.S. (2019). Caravelas à vista: Giros decoloniais e caminhos de resistência na formação de professoras e professores que ensinam matemática. Perspectivas da Educação Matemática, 12(30), 467-501, 2019.

Giraldo, V. (2018). Formação de professores de matemática: para uma abordagem problematizada. Ciência \& Cultura, 70, 37-42.

Giraldo, V. (2019). Que matemática para a formação de professores? Por uma matemática problematizada. Anais do XIII Encontro Nacional de Educação Matemática, Sociedade Brasileira de Educação Matemática.

Krenak, A. (2019). Ideias para adiar o fim do mundo. Rio de Janeiro, Brasil: Companhia das Letras.

Lander, E. (2001). Pensamiento crítico latinoamericano: la impugnación del eurocentrismo. Revista de Sociologia, 15, 13-25.

Mbembe, A. (2018). Necropolítica. São Paulo, Brasil: N-1 Edições.

Quijano, A. (2000). Colonialidad del poder, eurocentrismo y América Latina. Em: E. Lander (Edit.), La colonialidad del saber: eurocentrismo y ciencias sociales (pp. 201-246) Buenos Aires, Argentina: CLACSO.

Ramose, M. (2011). Sobre a legitimidade e estudo da filosofia africana. (D. Solis, Trad.) Ensaios Filosóficos, IV, 9-25.

Roque, T. (2020). Ciência e política em tempos de negacionismo. Ciência Hoje, 367, 1-10.

Rufino, L. (2018). Pedagogias das encruzilhadas. Revista Periferia, 10(1), 71-88.

Rufino, L. (2019). Pedagogias das encruzilhadas. Rio de Janeiro, Brasil: Mórula.

Santos, B. S. (2019). O fim do império cognitivo: a afirmação das epistemologias do Sul. Belo Horizonte, Brasil: Autêntica. 
Simas, L. A. \& Rufino, L. (2018). Fogo no mato: a ciência encantada das macumbas. Rio de Janeiro, Brasil: Mórula.

Walsh, C. (2008). Interculturalidad, plurinacionalidad y decolonialidad: las insurgencias político-epistémicas de refundar el Estado. Tabula Rasa, 9, 131-152.

Walsh, C. (2013). Lo pedagógico y ló decolonial: entretejiendo caminos. Em: C. Walsh (Org.), Pedagogías decoloniales: prácticas insurgentes de resistir, (re)existir y (re)vivir (pp. 23-68) Quito, Equador: Abya Yala. 